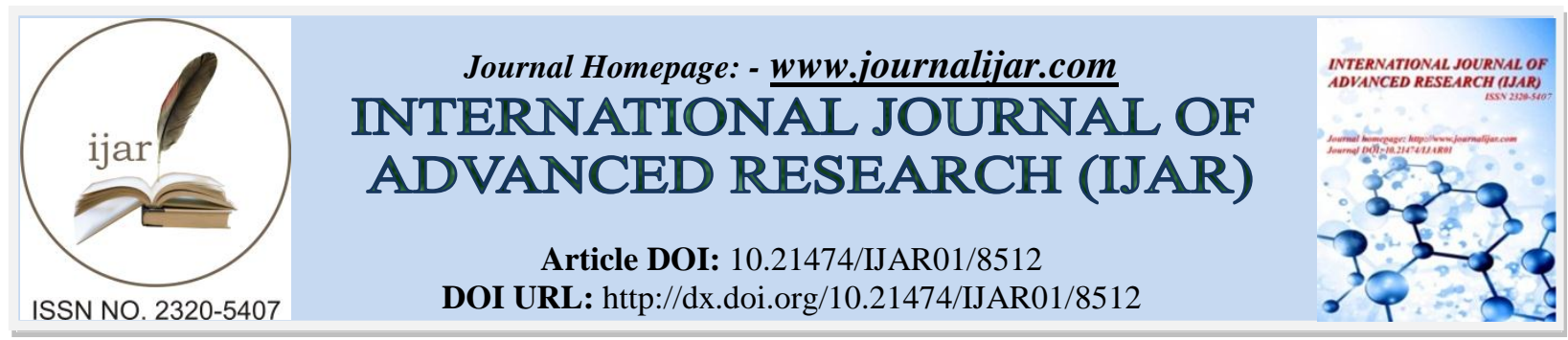

RESEARCH ARTICLE

\title{
ENDOVASCULAR MANAGEMENT OF CENTRAL VEIN LESIONS IN PATIENTS WITH LONG TERM HEMO-DIALYSIS THROUGH UPPER LIMB ARTERIO-VENOUS FISTULA- A SINGLE CENTRE RETROSPECTIVE STUDY.
}

M Bakthavatchalam, Balakumar and Sasikumar Sakthivelan.

\section{Manuscript Info}

Manuscript History

Received: 05 December 2018

Final Accepted: 07 January 2019

Published: February 2019

Key words:-

Angioplasty; central venous stenosis; endovascular; hemodialysis; stenting.

\begin{abstract}
Background: Central venous disease is a serious complication in patients undergoing hemodialysis, often presenting with symptoms of venous hypertension. Treatment is aimed to provide symptomatic relief and to maintain hemodialysis access site patency.

Aim: To describe our initial experience in the endovascular treatment of central venous stenosis or obstruction in patients undergoing hemodialysis.

Settings and Design: This was a retrospective study carried out in a tertiary care center. Study duration was 24 months. Follow-up was variable.

Materials and Methods: Fourteen patients of chronic renal failure undergoing hemodialysis presented with central vein stenosis or obstruction having ipsilateral vascular access, between January 2017 and December 2018. All the patients underwent endovascular treatment and were analyzed retrospectively.

Results and Conclusion: A total of 14 patients (12 male and 2 female) underwent 18 interventions for 13 stenotic segments during a time period of 2 years. Ten stenotic segments were in brachiocephalic vein, four in subclavian vein. The technical success rate for endovascular treatment was $71.4 \%$. All underwent percutaneous transluminal angioplasty (PTA) alone and four presented with restenosis later. Repeat Balloon angioplasty was done in four patients, two of which required $>=2$ reinterventions during follow - up. We found endovascular treatment safe and effective in treating central venous disease.
\end{abstract}

Copy Right, IJAR, 2019,. All rights reserved.

\section{Introduction:-}

Central venous stenosis and obstruction is a major concern in patients undergoing prolonged hemodialysis causing significant morbidity with access site dysfunction. Central venous disease (CVD) has been defined as 50\% or greater stenosis involving the internal jugular, subclavian, or axillary veins.[1] Incidence of central venous stenosis is 25-40\%.[2,3] The main causes of central venous stenosis in hemodialysis patients are prolonged central venous catheterization and high-flow status in arteriovenous fistula (AVF) or graft, subsequently causing venous intimal hyperplasia and stenosis.[2,4] Clinically, central venous stenosis manifests as ipsilateral arm or neck swelling, elevated venous pressure during hemodialysis, and failure of hemodialysis access. 
The aim of the treatment is to provide symptomatic relief to the patients while preserving the function of AVF.[5] Surgical and endovascular treatments are available for treatment of central venous stenosis. However, the optimal treatment is yet to be determined. Though high primary patency rates (80-90\% at 1 year) have been reported with open surgical repair of the central veins,[6] it carries a high rate of postoperative morbidity and mortality. Endovascular management has been widely accepted as the modality of choice for treatment of central venous stenosis.[7-9] Endovascular treatment options include percutaneous transluminal angioplasty (PTA), bare metal stent or covered stent placement. The optimal endovascular treatment, however, remains unclear, with no clear advantage of primary stent placement in comparison to angioplasty.[10-12].

The National Kidney Foundation Disease Outcomes Quality Initiative guidelines[13] have recommended angioplasty as the preferred treatment for CVD, with or without stent placement. In this retrospective study, we evaluated the outcomes of balloon angioplasty and stenting for management of central venous stenosis or occlusion in patients undergoing hemodialysis.

\section{Materials and Methods:-}

This was a retrospective study approved by the departmental ethical committee. Informed written consent was obtained from all the patients. A total of 14 patients with central venous stenosis or occlusion underwent endovascular treatment in our department. All the patients were on hemodialysis for chronic renal failure. Mean duration of dialysis before the intervention was 2.5 years (range: 3 months -4.5 years). All 14 cases had autogenous AVF for dialysis access. Indications for treatment were excessive swelling in the arm, decreasing flow during dialysis session, and pronged bleeding after cannulation. Pre-procedure contrast-enhanced CT (CECT) was done in 2 patients who were referred from other private hospitals for treatment in our hospital. we do not perform pre procedure ct in order to avoid contrast overdose. In all the patients, a preliminary diagnostic venography was performed with digital subtraction angiography. Location, length, and extent of stenosis/obstruction were assessed. Endovascular interventions were performed in the same sitting.

Venous access was obtained through cephalic vein in 2 cases. In two cases, ante grade venous puncture was done through common femoral vein and in 4 cases basilic vein accessed to tackle the lesion. In the remaining six cases, a combined approach using both cephalic and common femoral veins was used. Though approach through cephalic vein was preferred, femoral venous puncture was used to obtain access in difficult cases. After obtaining the access, the access site was secured using short 7F sheath (compatible with balloon and stent placement). A long sheath was used in cases of femoral approach to avoid traversing through the heart repeatedly. The stenotic site was traversed using a 0.035 -inch hydrophilic guide wire (Terumo, NJ, USA). For some hard obstructing lesions, the stiff end of the guide wire was also used. Diagnostic catheters and multipurpose catheters were used. After traversing the lesion, hydrophilic guide wire was replaced by exchange length stiff guide wire (Amplatz ; Boston scientific, Marlborough, USA) and PTA was performed subsequently. PTA balloon diameter ranged from 10 to $14 \mathrm{~mm}$ with burst pressures between 20 and 25 atmosphere. Length of the balloons ranged from 4 to $8 \mathrm{~cm}$. The various balloons used were: Mustang(Boston Scientific)), Atlas (Bard Inc., USA), and Armada ( Abbot). A balloon having diameter of 1-2 mm larger than the adjacent normal vein was selected and angioplasty was done by inflating the balloon for 3-5 min. Stenting was not performed.

Technical success was defined as procedure without significant residual stenosis or without complications. Technical failure was defined as inability to cross/dilate the lesion or significant residual stenosis ( $>30 \%$ ). A complication was defined as any event which is not routinely observed after the procedure, requiring treatment with endovascular or surgical intervention. Follow-up was censored for patient death, loss to follow-up, and closure or occlusion of the ipsilateral vascular access.

\section{Results:-}

A total of 14 patients underwent 18 interventions for endovascular treatment of CVD. The study comprised 12 men and 2 women with a mean age of 46 years (range, 25-73 years). Eight patients had involvement of right-sided venous system and six patients had involvement of the left side. A total of 14 diseased segments were identified with complete occlusion in 4 segments and stenosis in 10 segments. Ten diseased segments were identified in brachiocephalic vein (seven in left and three in right), four in subclavian vein (right), The length of the stenotic segment was $3-5 \mathrm{~cm}$ in 12 patients and two patient had long segment involvement of $>5 \mathrm{~cm}$. Technical success was 
achieved in $71.4 \%$ cases . In four patients, the occluded segment could not be negotiated. There was localized tear while negotiating the guidewire through the occluded segment, resulting in contrast extravasations in two patients. The procedure was abandoned at this point. Repeat venograms done in these patients showed spontaneous cessation of extravasation, thus obviating the need for further intervention to stop bleeding. In the remaining 10 cases, only PTA was done. [Figures 1 and 2]. Symptomatic improvement was reported in all the patients with no major periprocedural morbidity or mortality. Early complications encountered were local extravasation in two cases (following which the procedure was abandoned. Repeat PTA was done in 4 patients. A total of two patients required more than two interventions. Dialysis access site failure was seen in 4 patients. . In two cases, failure was due to thrombosis of AVF. In two cases, access site was abandoned due to poor functional status with creation of new autogenous AVF at a different site. Immediate complication encountered was localized extravasation during difficult manipulation of the guidewire. Delayed complications were restenosis . Proper follow-up of all the patients was not available. Patients presented to our center only if they had venous restenosis. Hence, due to lack of strict follow-up, the patency rates and long-term outcome could not be assessed.
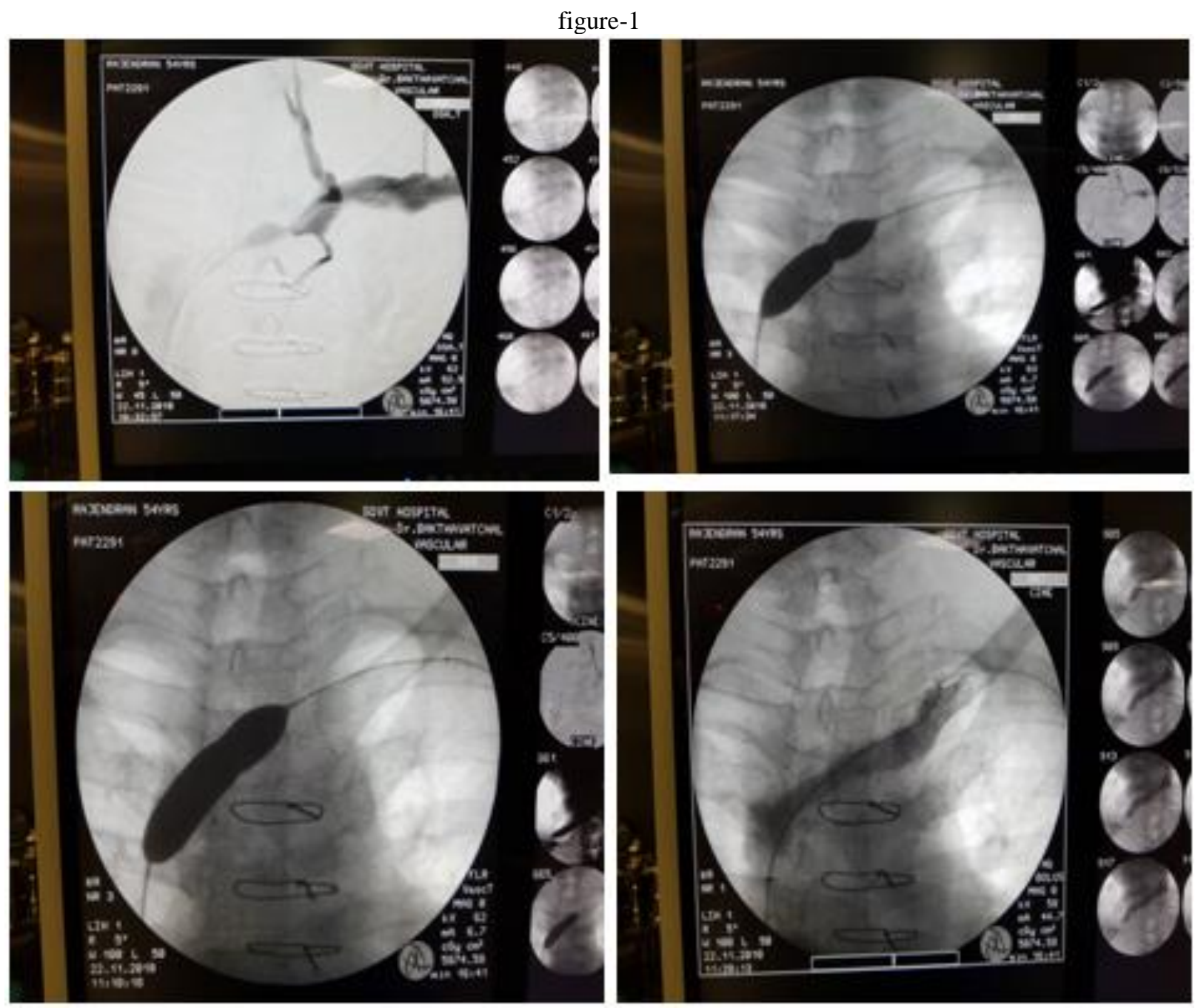


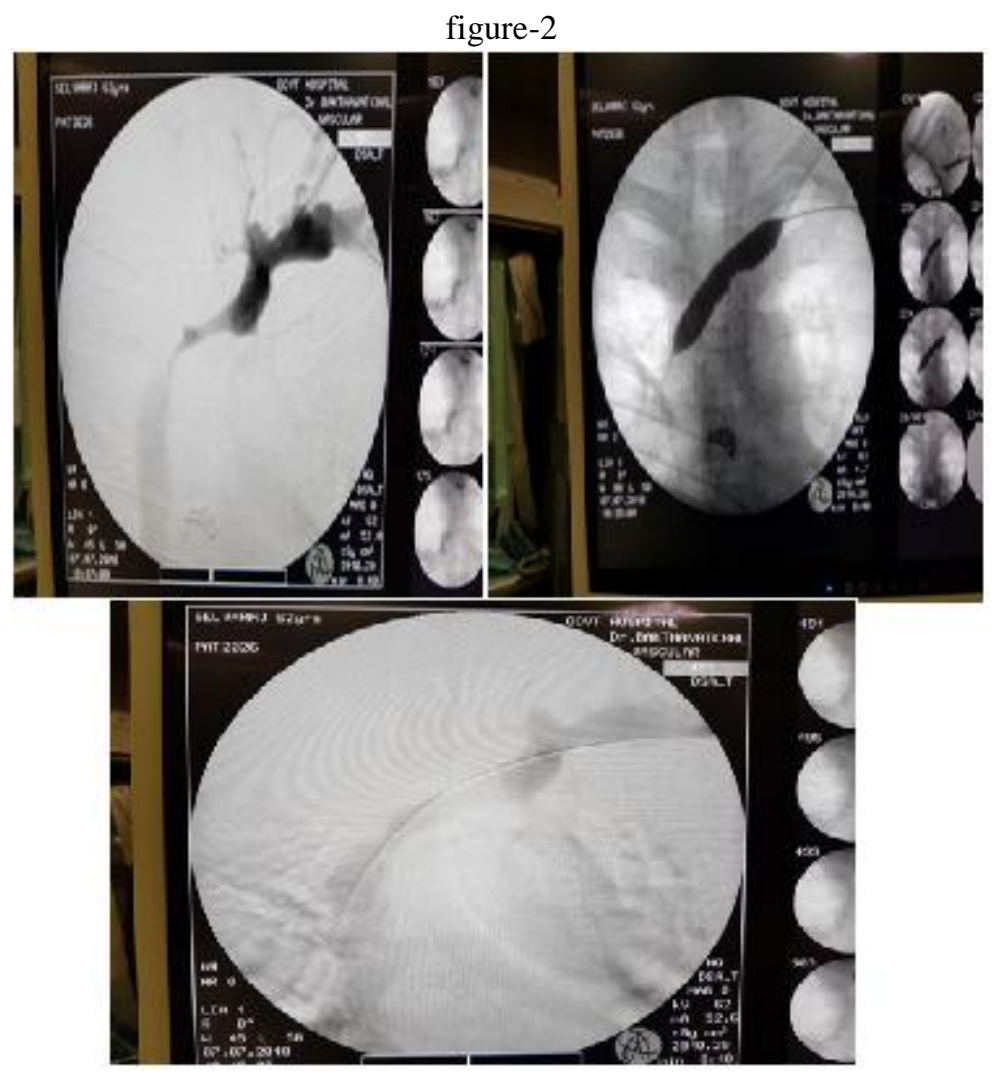

\section{Discussion:-}

In recent years, there has been substantial increase in complications related to dialysis access due to increasing number of patients with end-stage renal disease and their increased survival.[14] CVD is a prevalent condition in patients undergoing hemodialysis. Two major factors implicated in development of CVD are venous trauma resulting from cannulation of central veins and hemodynamic stress secondary to high flow due to access site AVF.[3,15] Central vein cannulation site determines central venous occlusion. Venous stenosis has been reported in up to $50 \%$ patients with catheterization of subclavian veins.[2,16] On the other hand, right internal jugular vein cannulation has been associated with the lowest frequency of CVD.[17].

The Dialysis Outcome and Quality Initiatives (DOQI) guidelines have advocated avoiding catheterization of subclavian vein in chronic renal failure patients for obtaining temporary access.[13] Development of central venous stenosis leads to increase in arteriovenous pressure at the dialysis access site. The resultant venous hypertension causes significant local morbidity by causing extremity, neck, and chest swelling. The initial management strategies were either surgical ligation of the fistula followed by abandonment of dialysis access site or open surgical repair of the central veins. Despite having high primary patencies at 1 year $(80-86 \%)$, surgical methods carried high morbidity.[18,19] In the 1980s, evaluation of various endovascular methods was started for treating central venous stenosis.[20] At present, endovascular treatment is the treatment of choice for CVD. The various endovascular methods used are balloon angioplasty, stenting, and, more recently, cutting balloon angioplasty. The optimal management strategy is still not clear. Primary stenting has been advocated by some for the treatment of CVD, [9,21] while others have advocated balloon angioplasty as the primary treatment, reserving stenting for treatment failure or restenosis.[10,12,22].

In this retrospective study, we have reported our initial experience in endovascular treatment of CVD in patients having ipsilateral dialysis access. Initial technical success rate in our case series was 71.4\%. In cases of technical failure, the guidewire could not be negotiated through completely occluded venous segment in the right brachiocephalic vein in two cases and innominate vein in 2 cases. For PTA, technical success rate ranging from 70 to $90 \%$ has been reported in the literature.[3,10-12,23-25] Very high technical success rates have been reported for bare metallic stenting in the literature, ranging from 90 to $100 \% \cdot[8,9,22,26-28]$ We performed only PTA in two 
patients [Figure 6]. No immediate complications were encountered. Both the patients presented with restenosis. Mean intervention-free period in these patients was 3.5 months(2-5 months). Elastic recoil is thought to be the cause for early recurrence in patients undergoing PTA.[29] In previous studies, primary patency rates for PTA ranged from 23 to 55\% at 6 months and from 12 to $50 \%$ at 12 months. Cumulative patency rates range from 29 to $100 \%$ and from 13 to $100 \%$ at 6 and 12 months, respectively.[3,10,23-25] In the remaining seven patients, PTA with stenting was performed [Figure 6]. We used self-expanding nitinol stent. Though nitinol stents are known to provide greater flexibility and resistance against kinking, in two previous studies, no significant difference was found between the patencies of wallstents and nitinol-based stents.[7,30] However, in another study, nitinol stents provided better patency rates than wallstents.[31] More recently, covered stents have also been utilized for treatment of central venous stenosis. High technical success rate with favorable outcomes have been reported in the limited literature available on the efficacy of covered stents.[32-35] Thus, covered stents appear to be an effective endovascular treatment option. However, their cost remains the limiting factor and cost/benefit analysis should be considered. Four patients presented with recurrent stenosis and two patients had repeat intervention with PTA twice after initial intervention. Time for reintervention ranged from 6 to 8 months. Hemodynamic stress and turbulence due to high blood flow in AVF has been implicated in causing intimal hyperplasia, thereby leading to stent restenosis.[36] With bare metallic stenting, primary patency rates of $63-100 \%$ at 3 months, $42-89 \%$ at 6 months, and $14-73 \%$ at 12 months have been reported. Cumulative patency rates range from 72 to $100 \%$, from 55 to $100 \%$, and from 31 to $97 \%$ at 3, 6, and 12 months, respectively.[8,9,11,22,26-28,37] Delayed complication of stent fracture was also seen in one case. Our study had certain limitations. Firstly, it was a non-randomized retrospective study. Secondly, the number of patients was very less with inadequate follow-up. Thus, patency rates could not be calculated. However, we have reported only our initial experience and further studies for longer time duration and with a larger sample size will be needed to assess long-term outcomes in the Indian population.

\section{Conclusion:-}

To conclude, the endovascular treatment is an effective and safe method for treatment of CVD in patients undergoing hemodialysis. It has a high technical success rate without significant morbidity or mortality. However, multiple reinterventions are required for treatment of restenosis.

\section{Financial support and sponsorship}

Nil.

\section{Conflicts of interest}

There are no conflicts of interest.

\section{References:-}

1. Modabber M, Kundu S. Central venous stenosis in haemodialysis patients: An update. Cardiovasc Intervent Radiol 2013;36:898-903.

2. Lumsden AB, MacDonald MJ, Isiklar H, Martin LG, Kikeri D, Harker LA, et al. Central venous stenosis in the hemodialysis patient: Incidence and efficacy of endovascular treatment. Cardiovasc Surg 1997;5:504-9.

3. Glanz S, Gordon DH, Lipkowitz GS, Butt KM, Hong J, Sclafani SJ. Axillary and subclavian stenosis: Percutaneous angioplasty. Radiology 1988;168:371-3.

4. Schwab SJ, Quarles LD, Middleton JP, Cohan RH, Saeed M, Dennis VW. Hemodialysis-associated subclavian vein stenosis. Kidney Int 1988;33:1156-9.

5. Sprouse LR 2nd, Lesar CJ, Meier GH 3rd, Parent FN, Demasi RJ, Gayle RG, et al. Percutaneous treatment of symptomatic central venous stenosis [corrected]. J Vasc Surg 2004;39:578-82.

6. Mickley V. Central vein obstruction in vascular access. Eur J Vasc Endovasc Surg 2006;32:439-44.

7. Masková J, Komárková J, Kivánek J, Danes J, Slavíková M. Endovascular treatment of central vein stenoses and/or occlusions in hemodialysis patients. Cardiovasc Intervent Radiol 2003;26:27-30.

8. Aytekin C, Boyvat F, Yagmurdur MC, Moray G, Haberal M. Endovascular stent placement in the treatment of up-per extremity central venous obstruc-tion in hemodialysis patients. Eur J Radiol 2004;49:81-5.

9. Haage P, Vorwerk D, Piroth W, Schuermann K, Guenther RW. Treatment of hemodialysis related central venous stenosis or occlusion: Results of primary Wallstent placement and follow-up in 50 patients. Radiology 1999;212:175-80. 
10. Surowiec SM, Fegley AJ, Tanski WJ, Sivamurthy N, Illig KA, Lee DE, et al. Endovascular management of central venous stenoses in the hemodialysis patient: Results of percutaneous therapy. Vasc Endovascular Surg 2004;38:349-54.

11. Bakken AM, Protack CD, Saad WE, Lee DE, Waldman DL, Davies MG. Long-term outcomes of primary angio-plasty and primary stenting of central venous stenosis in hemodialysis patients. J Vasc Surg 2007;45:776-83.

12. Quinn SF, Schuman ES, Demlow TA, Standage BA, Ragsdale JW, Green GS, et al. Percutaneous transluminal angio-plasty versus endovascular stent placement in the treatment of venous stenoses in patients undergoing hemodialysis: Intermediate results. J Vasc Interv Radiol 1995;6:851-5.

13. III. NKF-K/DOQI Clinical Practice Guidelines for Vascular Access: Update 2000. Am J Kidney Dis 2001;37(Suppl 1):S137-81.

14. Nael K, Kee ST, Solomon H, Katz SG. Endovascular management of central thoracic veno-occlusive diseases in hemodialysis patients: A single institutional experience in 69 consecutive patients. J Vasc Interv Radiol 2009;20:46-51.

15. Morosetti M, Meloni C, Gandini R, Galderisi C, Pampana E, Nicoletti M, et al. Late symptomatic venous stenosis in three hemodialysis patients without previous central venous catheters. Artif Organs 2000;24:929-31.

16. Hernández D, Díaz F, Rufino M, Lorenzo V, Pérez T, Rodríguez A, et al. Subclavian vascular access stenosis in dialysis patients: Natural history and risk factors. J Am Soc Nephrol 1998;9:1507-10.

17. Schillinger F, Schillinger D, Montagnac R, Milcent T. Central venous stenosis in hemodialysis: Comparative angiographic study of subclavian and internal jugular access. Nephrologie 1994;15:129-31.

18. Wisselink W, Money SR, Becker MO, Rice KL, Ramee SR, White CJ, et al. Comparison of operative reconstruction and percutaneous balloon dilatation for central venous obstruction. Am J Surg 1993;166:200-5.

19. Money S, Bhatia D, Daharamsy S, Mulingtapang R, Shaw D, Ramee S. Comparison of surgical bypass, percutaneous balloon dilatation (PTA), and PTA with stent placement in the treatment of central venous occlusion in the dialysis patient: One year follow-up. Int Angiol 1995;14:176.

20. Glanz S, Gordon D, Butt KM, Hong J, Adamson R, Sclafani SJ. Dialysis access fistulas: Treatment of stenoses by transluminal angioplasty. Radiology 1984;152:637-42.

21. Oderich GS, Treiman GS, Schneider P, Bhirangi K. Stent placement for treatment of central and peripheral venous obstruction: A long-term multi-institutional experience. J Vasc Surg 2000;32:760-9.

22. Gray RJ, Horton KM, Dolmatch BL, Rundback JH, Anaise D, Aquino AO, et al. Use of Wallstents for hemodialysis access-related venous stenoses and occlusions untreatable with balloon angioplasty. Radiology 1995;195:479-84.

23. Beathard GA. Percutaneous transvenous angioplasty in the treatment of vascular access stenosis. Kidney Int 1992;42:1390-7.

24. Kovalik EC, Newman GE, Suhocki P, Knelson M, Schwab SJ. Correction of central venous stenoses: Use of angioplasty and vascular Wallstents. Kidney Int 1994;45:1177-81.

25. Dammers R, de Haan MW, Planken NR, van der Sande FM, Tordoir JH. Central vein obstruction in hemodialysis patients: Results of radiological and surgical intervention. Eur J Vasc Endovasc Surg 2003;26:317-21.

26. Vogel PM, Parise C. SMART stent for salvage of hemodialysis access grafts. J Vasc Interv Radiol 2004;15:1051-60.

27. Vesely TM, Hovsepian DM, Pilgram TK, Coyne DW, Shenoy S. Upper extremity central venous obstruction in hemodialysis patients: Treatment with Wallstents. Radiology 1997;204:343-8.

28. Vorwerk D, Guenther RW, Mann H, Bohndorf K, Keulers P, Alzen G, et al. Venous stenosis and occlusion in hemodialysis shunts: Follow-up results of stent placement in 65 patients. Radiology 1995;195:140-6.

29. Kim YC, Won JY, Choi SY, Ko HK, Lee KH, Lee do Y, et al. Percutanous treatment of central venous stenosis in haemodialysis patients: Long-term outcomes. Cardiovasc Intervent Radiol 2009;32:271-8.

30. Maya ID, Saddekni S, Allon M. Treatment of refractory central vein stenosis in hemodialysis patients with stents. Semin Dial 2007;20:78-82.

31. Rajan DK, Saluja JS. Use of nitinol stents following recanalization of central venous occlusions in hemodialysis patients. Cardiovasc Intervent Radiol 2007;30:662-7.

32. Quinn SF, Kim J, Sheley RC. Transluminally placed endovascular grafts for venous lesions in patients on hemodialysis. Cardiovasc Intervent Radiol 2003;26:365-9.

33. Kundu S, Modabber M, You JM, Tam P, Nagai G, Ting R. Use of PTFE stent grafts for hemodialysis-related central venous occlusions: Intermediate-term results. Cardiovasc Intervent Radiol 2011;34:949-57. 
34. Anaya-Ayala JE, Smolock CJ, Colvard BD, Naoum JJ, Bismuth J, Lumsden AB, et al. Efficacy of covered stent placement for central venous occlusive disease in hemodialysis patients. J Vasc Surg 2011;54:754-9.

35. Jones RG, Willis AP, Jones C, McCafferty IJ, Riley PL. Long-term results of stent-graft placement to treat central venous stenosis and occlusion in hemodialysis patients with arteriovenous fistulas. J Vasc Interv Radiol 2011;22:1240-45.

36. Fillinger MF, Reinitz ER, Schwartz RA, Resetarits DE, Paskanik AM, Bruch D, et al. Graft geometry and venous intimal-medial hyperplasia in arteriovenous loop grafts. J Vasc Surg 1990;11:556-66.

37. Chen CY, Liang HL, Pan HB, Chung HM, Chen WL, Fang HC, et al. Metallic stenting for treatment of central venous obstruction in hemodialysis patients. J Chin Med Assoc 2003;66:166-72. 